\title{
Seeing the Light: Science Communication and Art
}

\author{
Margaret Wegener ${ }^{\mathrm{a}}$, Samantha Littley ${ }^{\mathrm{b}}$ \\ Corresponding author: Margaret Wegener (wegener@physics.uq.edu.au) \\ ${ }^{a}$ School of Mathematics and Physics, The University of Queensland, Brisbane QLD, Australia \\ ${ }^{\mathrm{b}} \mathrm{UQ}$ Art Museum, The University of Queensland, Brisbane QLD, Australia
}

Keywords: science communication, physics, art, interdisciplinary, communication skills

\begin{abstract}
A collaboration connecting a university's Physics teaching and its art museum's exhibition program has demonstrated the value of such partnerships. In the context of an upsurge in transdisciplinary art practice, and the need for scientists to develop skills in communicating science to non-specialists, a curator and a physicist implemented an innovative learning and assessment activity associated with a significant exhibition of contemporary art. Third-year physics students were tasked with selecting an artwork from the exhibition and explaining the physics in it to gallery visitors, via a short piece of writing. A selection of the best student-authored texts was displayed in the exhibition alongside the usual curatorial labels. In preparing for the task, students were given instruction and practice in writing about science for non-scientists, and provided with information about the artworks and the exhibition. The students' writing enriched the visitor experience by establishing links between art and science. Students saw their science in a new context. The nature of this activity as an authentic task with a genuine reward - the opportunity for public, professional output - had a positive effect on student engagement with science communication. We discuss the impact of the activity and the transferability of the strategies used.
\end{abstract}

\section{Introduction}

There is growing awareness of the need for scientists to be skilful at communicating science to nonspecialists. Our desire to address this with third-year Physics students coalesced with the prompt of the International Year of Light and Light-based Technologies (IYL, 2015), and our university art museum's aim to link its programming to the institution's teaching and learning. The International Year of Light was an initiative of the United Nations Educational, Scientific and Cultural Organisation (UNESCO). This 'Educational, Scientific and Cultural' remit inspired an innovative educational project linking science and culture. Together the authors (a Physics lecturer and an art curator) devised a novel educational experience around an art exhibition on the theme of light - Light Play: Ideas, Optics, Atmosphere (UQ Art Museum, August - November 2015). As a science communication task, students were asked to write a label for one of the artworks in the exhibition, explaining the physics that it illustrates or uses, in an accessible and engaging way. They were informed that their work could end up on the gallery walls if judged to be of high quality. Thus, writing generated within the curriculum as part of formal learning activities and assessment offered the possibility of extra-curricular reward.

\section{The context}

Art-Science collaborations have proliferated in recent years, and have been the focus of several projects at The University of Queensland Art Museum (UQ Art Museum). An example is artist Peter Hennessey's residency with hypersonic aerodynamics researchers at this university. In an artwork resulting from the project, Celestial choreography \#1 (Re-entry re-enactment) 2014-2015, Hennessey noted similarities in the clichés of the 'MAD SCIENTIST' and 'CRAZY ARTIST' and their ways of working, including with regard to "COMMUNICATION - (SOMETIMES GOOD, SOMETIMES BAD) OFTEN MISUNDERSTOOD”. (Hennessey cited in Littley et al., 2015, pp. 48-49). The communication skills of scientists (or the lack thereof) has been a subject of interest in education research. One finding is that employers of Australian science graduates have perceived a deficit in graduates' written communication 
skills; these employers want graduates who can communicate with a wide range of people, and who are able to translate science terminology and ideas so that they are understandable by diverse others (McInnis, Hartley, \& Anderson, 2000). It has been acknowledged that the ability to communicate with a range of audiences about science is one of the fundamentals that a student 'should know and be able to do' upon graduating with a bachelor degree in science (Jones, Yates, \& Kelder, 2011), and specifically in Physics (Wegener, 2013). For those graduates who work in research, there is increasing emphasis on ensuring the impact of their scientific labours. This includes disseminating their work via non-traditional outputs, such as online postings, for example The Conversation (2019), that are likely to have many more readers than a specialist academic journal. When applying for funding, researchers often have to write a justification/motivation for a lay audience (or at least scientists outside their own field). Despite these circumstances, the vast majority of communication tasks that science students undertake throughout bachelor degrees in Australia consists of technical writing for scientists in the same discipline (Stevens, 2013, cited in Mercer-Mapstone \& Kuchel, 2015). Some physics students have a naïve belief that communicating to non-scientists will not be relevant to them unless they are going to become a science teacher. This kind of attitude makes engaging students in science communication a challenge.

At our institution, an Australian research-intensive university, we are addressing the imperative to improve skills in written communication for non-specialist audiences, in a 'capstone' course that undergraduate Physics students take in their last semester of study. A module in Science Communication occupies approximately one-third of the semester. It aims to assist students to combat the tendency to use jargon, and to encourage them to be concise and create text that is a pleasure to read!

There are instances of the use of non-technical writing in physics education, both formal and informal. For example, haiku (a poetry form that is extremely concise and rigorous in structure) has been used to express physics that has been learned - in a reflective process by first-year university students (Reflections: Physics Haiku, 2002), and written by postgraduate research students and staff at a physics research institute as part of its outreach program (PI-ku, 2017). Our students had also already been taught the relevant Physics before they were asked to write about it creatively; their task was to identify the Physics encapsulated in an artwork (ie: to transfer their existing knowledge to an unfamiliar situation). This project makes use of the wellknown educational strategy of explaining what you think you know to someone else in order to reinforce your own knowledge. In contrast, school students in the process of learning Physics have been given a view into the subject by analysing physics-inspired poetry composed by twentieth-century poet (and nonscientist) Robert Frost, who attended Physics seminars while a university academic (Abisdris \& Casuga, 2001).

In the last decade or so, there has been a groundswell of interest in interactions between science and art, and collaborations between the fields are now widespread. Artist-in-residence programs operate around the world, in university science departments and in research institutions such as the European Organization for Nuclear Research (CERN). The artistic research centre SymbioticA, based at the University of Western Australia, describes itself as 'an artistic laboratory' and 'the first research laboratory of its kind' (SymbioticA, 2019). Exemplifying its work, the 'Victimless Leather' project conceived by Oron Catts and Ionat Zurr has explored the ethics of tissue engineering through visual art (Victimless Leather 2004, Tissue Culture and Art Project cited in SymbioticA, 2013). The entire exhibition New Alchemists (Salamanca Arts Centre, 2016, and UQ Art Museum, 2017), which included this artwork, displayed a range of technologically-enabled transformations. Artists are utilising specialised equipment and techniques (necessary to access certain experiences) that were previously the domain of scientists; in parallel some scientists have recognised qualities of art in the artefacts of scientific research (Kleine and Settles, 2008). In each case, science is a stimulus for art. In this paper we discuss a project where scientists were encouraged to use artworks as their starting point. Our activity encouraged Physics students, who previously may not have stepped outside their discipline, to find the science in art.

Our project grew out of an initiative led by the current Director of UQ Art Museum, Dr Campbell Gray, who, from his appointment in 2011, has sought to embed the exhibition program in teaching and learning at the university. Curatorial staff have been encouraged to establish and foster creative, scholarly and pedagogical relationships across the campus (particularly beyond the related disciplines of Art History and 
Museum Studies), and to explore mutually beneficial collaborative ventures. The student engagement project developed for Light Play represents a tangible way in which this imperative has been implemented.

\section{The exhibition}

Light Play was one of many enterprises around the globe conceived in response to IYL 2015 and its aim to establish 'global awareness about how light-based technologies promote sustainable development and provide solutions to global challenges in energy, education, agriculture and health' (IYL, 2015). These broad socio-political issues substantiated the relevance of an exhibition on the theme of light within the university context. The exhibition additionally had its genesis in the observation that an increasing number of contemporary artists are working with light, either as a medium and/or for its metaphorical associations. A desire to explore the reasons behind this phenomenon, and to place it in the context of art historical precedents, prompted further enquiry. Light, which is central to perception, has been an enduring subject in art. In prehistory, artists captivated by its perceived mystical qualities erected structures like Stonehenge to harness its power, while in later centuries painters such as the German Romantic Caspar David Friedrich were absorbed by light's emotive overtones or, like the Impressionists, sought to capture its ephemeral nature, an aim facilitated by the advent of photography. These movements were influenced by scientific developments, with advances in technology through the twentieth century leading to further experimentation. Artists equated artificial light with Modernist ideals and, as the century progressed, explored visual effects and movement in Op and Kinetic Art, and were subsequently engaged by the potential of fluorescence, neon and holography. This history informed research into the UQ Art Museum's primarily contemporary holdings, which in turn formed the basis of the exhibition and led to the development of ideas that would draw the collection and IYL together. In summary, the diverse approaches that contemporary artists are adopting in response to light, coupled with real world improvements - such as light-emitting diodes that are addressing environmental and humanitarian concerns - confirmed an exhibition about light would connect to the contemporary moment.

The authors' collaboration came into being via planning for IYL activities and awareness of each other through previous professional interaction. Curator Samantha Littley sought an academic partner within UQ Physics who would appreciate both the artistic aims of the exhibition and conceptualise it as part of UQ's broader academic aims. She approached Dr Margaret Wegener, cognisant of her interest in art through her own artistic practice. The collaboration dated from the early days of the exhibition's development. Usefully, Dr Wegener's physics research background in holography had introduced her to the work of holographic artist Paula Dawson, who Littley intended to feature in the exhibition - through Dr Wegener's association with Dawson, she facilitated the loan of a holographic artwork for the show. The curator and physicist wrote complementary academic essays for the exhibition catalogue, drawing on their own disciplinary viewpoints (Littley; Wegener in Light Play catalogue, 2015).

The three-month long exhibition showcased the work of more than 25 contemporary Australian artists including Brook Andrew, Bill Henson, and Jacky Redgate. Artworks were grouped into themes that are captured in the exhibition's subtitle: Ideas, Optics, Atmosphere. Light Play was supported by an innovative range of education programs - as well as the activity discussed in this paper, the exhibition inspired a concert of new work by the university's music students, and was the impetus for a cross-disciplinary masterclass for art and science high-school students.

The range of science embodied in the exhibition provided plenty of scope for discussion by the Physics students. All of the artworks involved concepts that had been addressed in first- or second-year university Physics, for example, refraction, reflection from curved surfaces, scattering of light by interaction with particles, light as a wave, interference, fluorescence, atomic energy levels, photons.

\section{The educational activity}

Third-year Physics students taking a science communication module were ultimately set the following task:

- Choose an artwork in the exhibition "Light Play" at the UQ Art Museum and identify physics relevant to it. Explain this physics to a visitor to the exhibition; 
- High-quality explanations will be submitted to the editorial process of the UQ Art Museum, for inclusion in the exhibition as information panels next to the artworks.

During the science communication module, students experienced instruction and practice in writing about science for non-scientists. The training classes were delivered by a postgraduate student in science communication, and included analysis of audience, 'translation' of science for particular audiences, and considerations of literary style and graphics (Mercer-Mapstone and Kuchel, 2016). As formative and summative exercises, students wrote a number of short pieces of text about Physics that should be familiar to them, aimed at a variety of audiences ranging in age, education and interests.

A scheduled class was dedicated to visiting the exhibition. (The Physics students are located on the same campus as the Art Museum.) Students were introduced to the exhibition and its themes by the curator. From their individual disciplinary perspectives, the curator and the physics lecturer discussed key artworks with students. The curator provided demographic information about the Art Museum's visitors, and described the purpose and form of interpretative labels in a gallery context. The students then spent time viewing the exhibition at their own pace, and chose the artwork they would write about.

The assessment task first challenged students to identify some Physics relevant to the artwork. This was to be expressed very succinctly (limit of 15 words). The answer could be as 'physicsy' as they liked. This was perfectly suited to using jargon. They then worked through a sequence adapted from activities originated by Mercer-Mapstone and Kuchel (2016) that aim to help them move beyond the physics-student headspace by explicitly considering the target audience. They were required to write a short (60 word) explanation of the identified Physics, including why it is relevant to the artwork, for an audience similar to themselves - a university student who has completed second-year Physics; then to identify terminology in that explanation that is inappropriate for the target audience, and provide better alternatives. This culminated in them writing an explanation of the relevant Physics for an exhibition visitor, in 150 words or less - a limit set by the art museum's standards. The entire task was worth $10 \%$ of the course.

The process of selecting which of these explanations would be displayed in the exhibition was carried out independently of marking for assessment. The curator and Physics lecturer critiqued the students' submissions and then made a selection, ensuring that a range of artworks were addressed, that there was a spread over the three rooms of the exhibition, and that a restriction of one Physics-related text per artwork was satisfied. As per the usual editorial process followed by the art museum, some minor edits were made. Successful students were notified via email. In that message, permission was addressed by including the final edited versions and informing students that they could decline to have this text made public, though none did.

From a total of twenty-eight submissions, eight student pieces were selected. They were displayed with the artworks, alongside and on par with the curator's text, during the latter part of the exhibition. Authors were named and identified as "UQ Physics student". These students thus had refereed public output in a professional setting.

\section{Student responses}

In the gallery a few students initially looked as if they felt out of their natural environment. Students gravitated to certain works while in the gallery. Some artworks prompted submissions from multiple students, and there were multiple good responses relating to some artworks. This occurred despite the number of artworks being similar to the number of students, the students appreciating that their chances of success in terms of public display would be higher if there was a greater spread amongst the artworks, and coverage across the exhibition being encouraged when they were choosing their artworks. This implies that personal reactions to the art were significant; this was borne out by student comments.

Examples of student work that was displayed in the exhibition are shown in Figure 1 below, with the corresponding artworks. 
(a) Artwork: Nell, The Dr. said it was like being hit by lightning

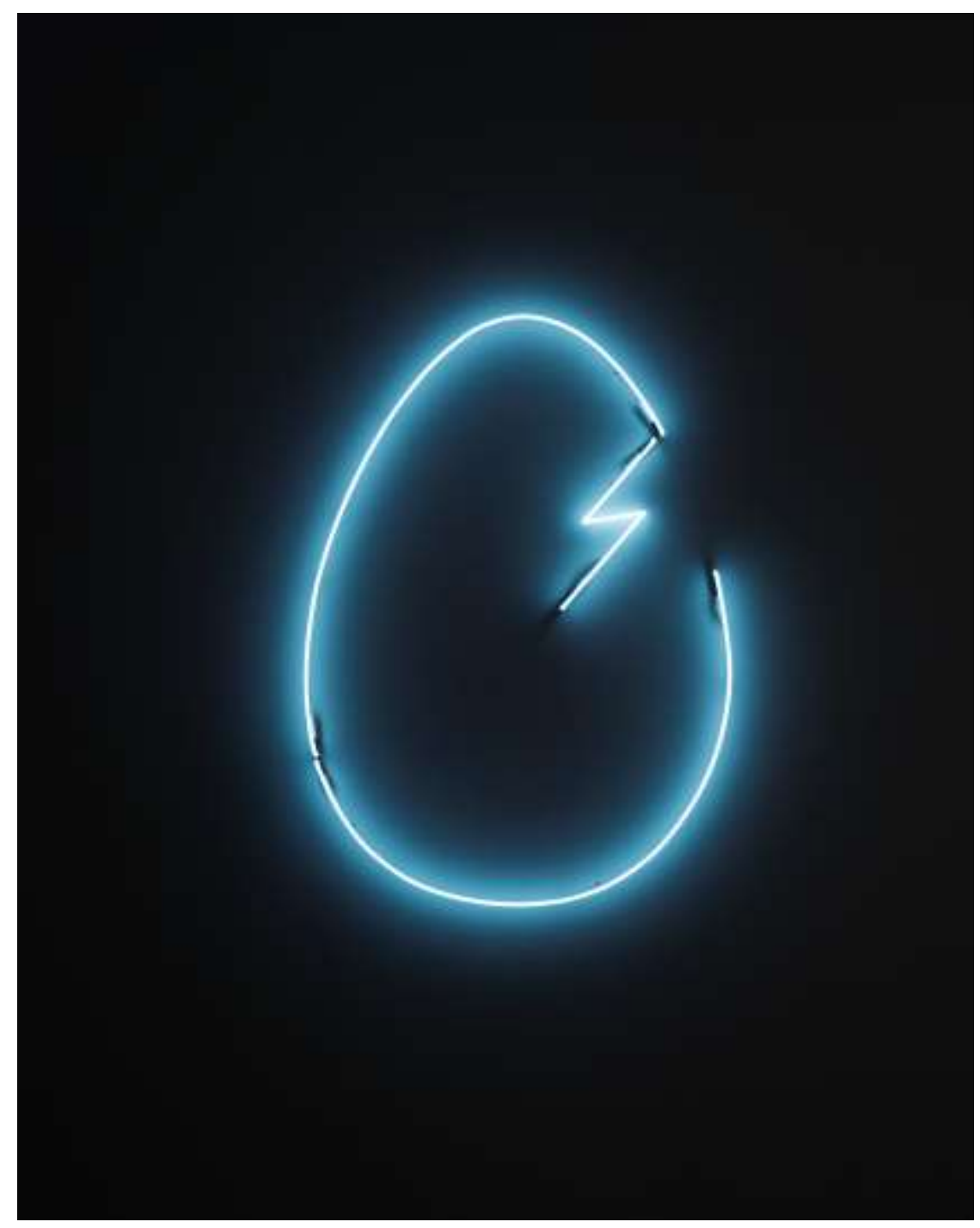

Light is the driving force behind all life. This work explores the inextricable link between these two concepts, juxtaposing an image of a cracked egg - a symbol of premature death with bold neon lighting. Sterile, white light emanates from the installation's glass tubes when an electric current, carried by the movement of miniscule, negatively charged particles called 'electrons', is passed through it. This is because these electrons collide with atoms of a gas trapped within the glass tube. Such a collision transfers energy to an atom where it 'excites' an electron bound to the atom's positively charged core to a higher energy level. When the 'excited' electron eases back to its original energy level, a particle of light carries away this energy, and the tube glows. The artist's emphasis on the 'lifeless', artificial light produced by this process suggests a reference to her intense grief at losing her child.

[Rebecca Chan, Physics student] 


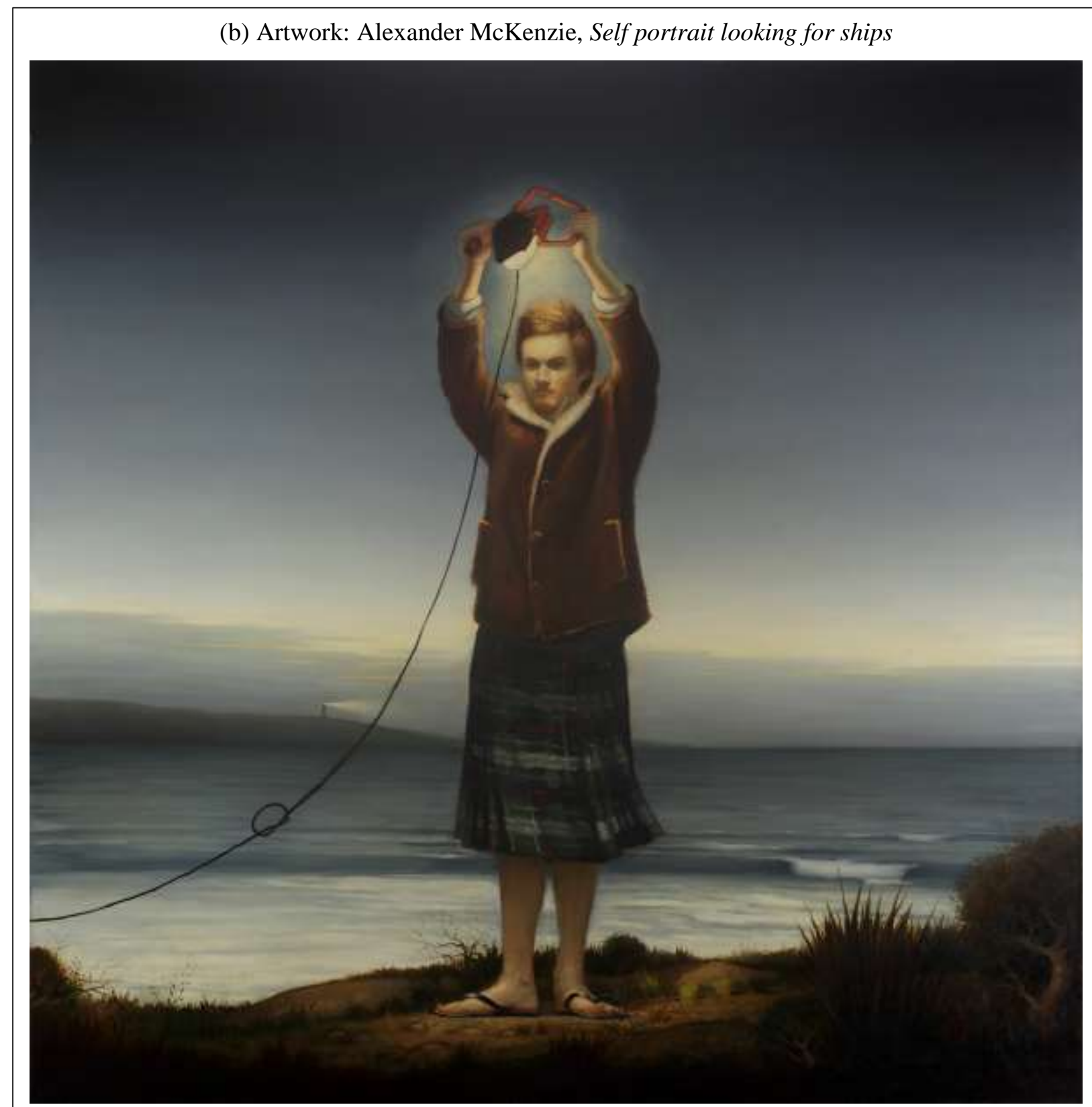

The power of this work comes from its use of light and colour to immerse the viewer in a twilit landscape. The subtle illumination that is observed during twilight is the result of an interaction between sunlight and the atmosphere. After sunset, no sunlight can reach the ground directly. Considering this alone, one would expect that the darkness of night would descend almost immediately. However, for a period of time after the sun has set, some sunlight still reaches the upper atmosphere. Once there, it comes into contact with the many small particles that make up our atmosphere. The sunlight then bounces off these particles in numerous directions, causing some light to reach the surface of the Earth. This creates the soft colours of a twilight sky with which we are all familiar, and which this painting depicts so beautifully.

[Alexander Johnston, Physics student] 


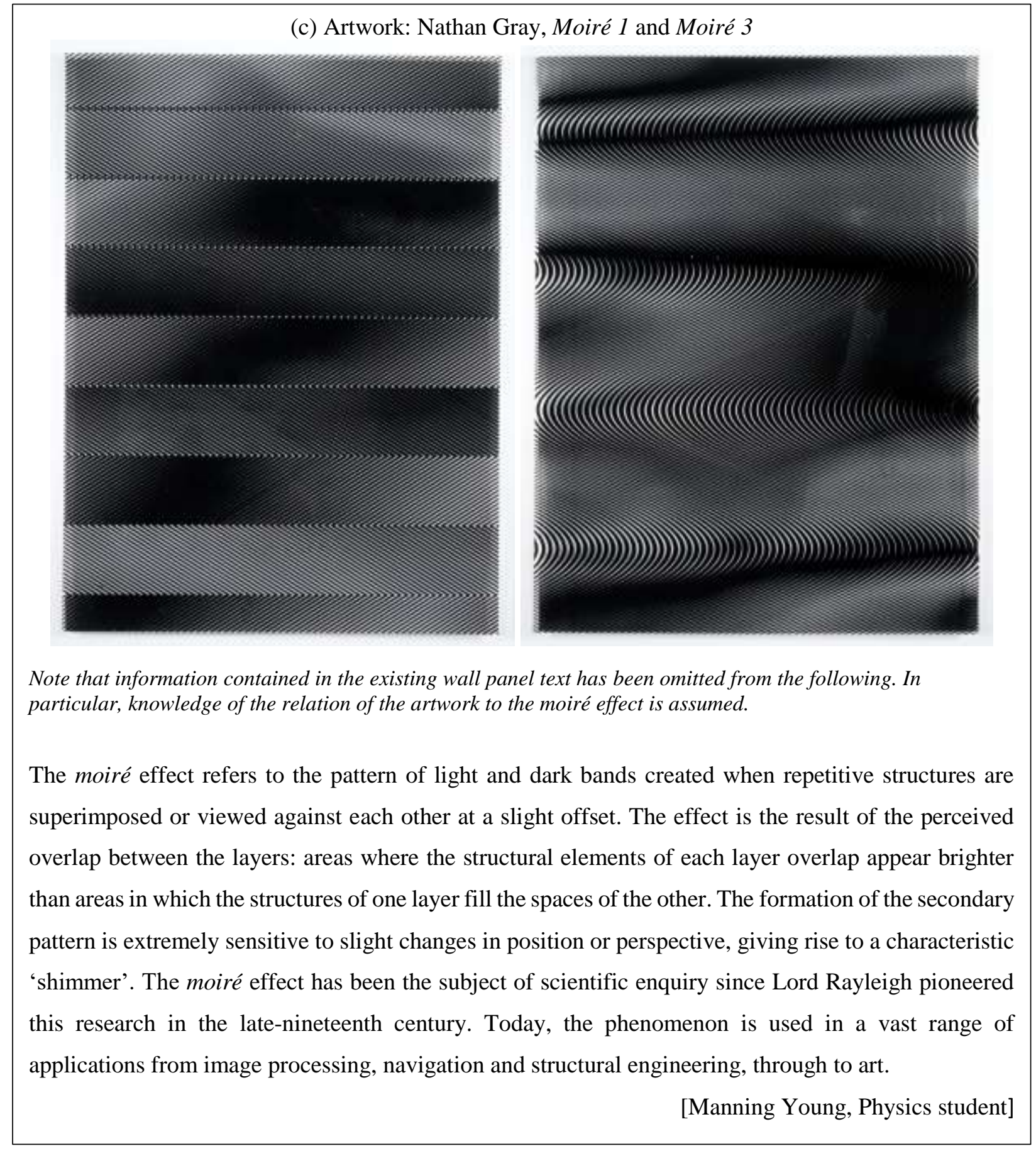

Figure 1: Examples of students writing to explain the Physics in artworks.

(a) Nell

The Dr. said it was like being hit by lightning 2013

neon, edition of $5+2 \mathrm{~A} / \mathrm{Ps}$

$156.0 \times 112.0 \mathrm{~cm}$

Collection of The University of Queensland, purchased 2015.

Reproduced courtesy of the artist and Roslyn Oxley9 Gallery, Sydney

Photo: Ivan Buljan

\section{(b) Alexander McKenzie}

Self portrait looking for ships 2006

oil on linen

$198.0 \times 198.5 \times 3.2 \mathrm{~cm}$ 
Collection of The University of Queensland. Gift of Alexander McKenzie through the

Australian Government's Cultural Gifts Program, 2009.

Reproduced courtesy of the artist and Martin Browne Contemporary, Sydney.

Photo: Carl Warner

\section{(c) Nathan Gray}

\section{Moiré 12010}

mixed media, edition $2 / 30$

$52.0 \times 39.0 \mathrm{~cm}$

Collection of The University of Queensland, purchased 2011.

Reproduced courtesy of the artist.

Photo Carl Warner and Nathan Gray

\section{Moiré 32010}

mixed media, edition $2 / 30$

$52.0 \times 39.0 \mathrm{~cm}$

Collection of The University of Queensland, purchased 2011.

Reproduced courtesy of the artist.

Photo Carl Warner

The quality of student work submitted was generally quite high. The range of performance by the class on the assessment task is indicated in Figure 2 (with 7 being the highest level of performance). One student failed the task (later withdrawing from the course); one student did not submit. Figure 2 shows that there is some correlation between the students' performance on this task and their overall course performance (which is dominated by their work on research projects). The pieces selected for display coincidentally were awarded high marks, enhancing confidence in the methods of assessment.

All students successfully identified Physics relevant to the artworks. They were able to connect familiar concepts to unfamiliar objects. In most cases, correct understanding of the relevant Physics was clearly evident in the explanations. It is known from discussions in and after class that multiple students read up on the related Physics when writing these pieces, in the process deepening and confirming their knowledge. Students' awareness of the target audience, and their consideration of what the audience was likely to know, showed in the way that the writing was aimed at a suitable level, with appropriate concepts and language used. Students responded to the artworks in different ways, with writing styles ranging from personal to more matter-of-fact. Amongst the best student work, metaphor was used as an effective mechanism to communicate with the target audience - especially notable since communication training had included a section on the use of metaphor. Overall, it's clear from the quality and sophistication of work done for this last assessment piece in the science communication module that students had progressed in science communication capability since the beginning of the module. 


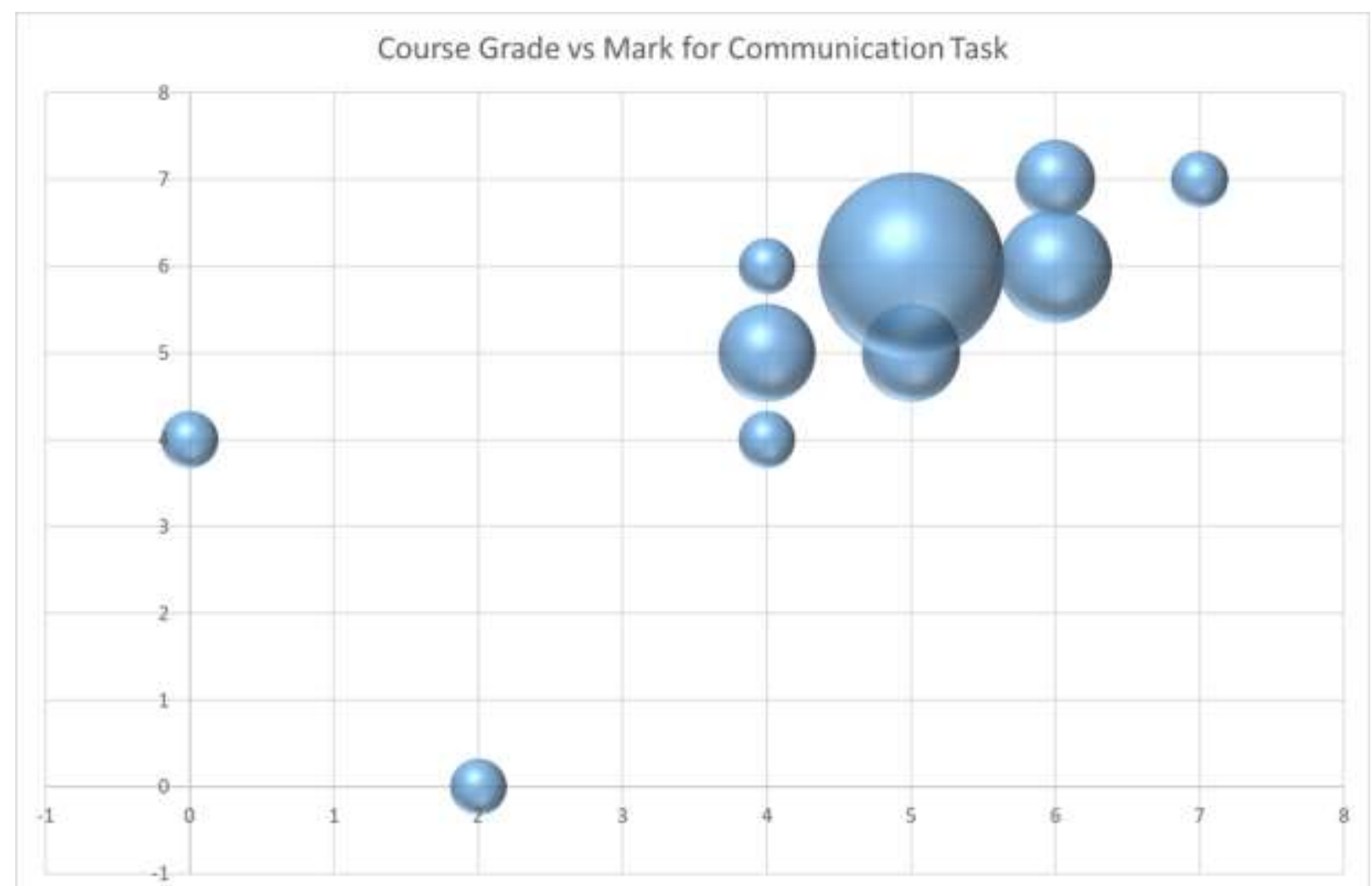

Figure 2: Students' grade for the course (on a scale of 1-7) compared to their mark for the assessment task of communicating the science in an artwork (on a scale of 1-7). The size of the bubble represents the number of students.

\section{Project reflections and discussion}

\section{Student reflections}

In informal discussions, multiple students volunteered the information that they were motivated to do this task well - and motivated differently from other assignments - by the chance that their work would be displayed in public. In the formal feedback of anonymous course evaluation, the activity was nominated as one of the best aspects of the capstone course as seen in the following comment:

...while [negative comment about science communication module as a whole], I did enjoy writing the description of the physics behind the artwork.

The students involved in this science-art activity were recently contacted, and asked to reflect on their experience of more than three years ago. Below are the reflections of some. The students whose work has been included here are a small sample of the class, but their current situations encompass common career pathways for Physics graduates. Table 1 shows their responses to two specific questions:

- Looking back, what did you get out of the experience of science meeting art?

- Since graduating with your Bachelor degree, have you needed to communicate about science to non-scientists? If yes, please say a little about the situation.

In the responses received from students, recurring themes were noted (see Table 1) including the realisations that art can help to communicate science, science can enhance the art experience, and communicating with people from a variety of educational backgrounds is of great practical importance in work/study situations. From this we can infer value in their student experience communicating science to non-specialists. 
Table 1: Long-term reflections of students

\begin{tabular}{|c|c|c|c|}
\hline Student & RC & AJ & MY \\
\hline $\begin{array}{l}\text { Current } \\
\text { situation }\end{array}$ & $\begin{array}{l}\text { Student in postgraduate } \\
\text { medical degree }\end{array}$ & $\begin{array}{l}\text { Student in Physics- } \\
\text { related } \mathrm{PhD}\end{array}$ & Employed in industry \\
\hline $\begin{array}{l}\text { Outcomes } \\
\text { from science- } \\
\text { meets-art } \\
\text { experience }\end{array}$ & $\begin{array}{l}\text { It struck me that while } \\
\text { 'art' and 'science' are } \\
\text { often portrayed as } \\
\text { polar opposites, they } \\
\text { are not mutually } \\
\text { exclusive. Art can be a } \\
\text { powerful medium in } \\
\text { conveying - and driving } \\
\text { - scientific innovation. }\end{array}$ & $\begin{array}{l}\text { Undertaking the } \\
\text { "science meets art" } \\
\text { project enabled me to } \\
\text { develop a new way of } \\
\text { thinking about both } \\
\text { disciplines. In } \\
\text { particular, it } \\
\text { demonstrated that art } \\
\text { can be used effectively } \\
\text { as a medium through } \\
\text { which to convey the } \\
\text { beauty and wonder of } \\
\text { science. }\end{array}$ & $\begin{array}{l}\text { It was a very direct } \\
\text { example of how } \\
\text { science, when } \\
\text { communicated } \\
\text { appropriately, can } \\
\text { complement art. Our } \\
\text { explanations offered an } \\
\text { additional layer of } \\
\text { understanding which } \\
\text { served to enhance the } \\
\text { artworks and perhaps } \\
\text { appeal to a non- } \\
\text { traditional audience. }\end{array}$ \\
\hline $\begin{array}{l}\text { Current need } \\
\text { to } \\
\text { communicate } \\
\text { about science } \\
\text { to non- } \\
\text { scientists }\end{array}$ & $\begin{array}{l}\text { Concisely explaining } \\
\text { scientific concepts to } \\
\text { non-scientists, such as } \\
\text { the pathophysiology } \\
\text { underlying a } \\
\text { disease or the } \\
\text { mechanism of action of } \\
\text { a medication, is vital in } \\
\text { the medical profession. } \\
\text { Furthermore, the ability } \\
\text { to talk about science, in } \\
\text { an accessible and } \\
\text { engaging manner } \\
\text { underpins the } \\
\text { effectiveness of science } \\
\text { education, regardless of } \\
\text { its target audience. }\end{array}$ & $\begin{array}{l}\text { I ... am often required } \\
\text { to communicate } \\
\text { science to non- } \\
\text { scientists. For } \\
\text { example, I was recently } \\
\text { required to give a } \\
\text { concise summary of my } \\
\text { research project at an } \\
\text { award ceremony of my } \\
\text { [scholarship] funding } \\
\text { body ... I had to draw } \\
\text { on my scientific } \\
\text { communication skills } \\
\text { in order to convey the } \\
\text { significance of the } \\
\text { research to an } \\
\text { audience of donors and } \\
\text { board members with a } \\
\text { variety of scientific and } \\
\text { non-scientific } \\
\text { backgrounds. }\end{array}$ & $\begin{array}{l}\text { I was fortunate enough } \\
\text { to land a position in } \\
\text { industry } \\
\text { (environmental } \\
\text { consulting) where } \\
\text { communication is a } \\
\text { routine and highly- } \\
\text { valued skill. The most } \\
\text { obvious scenario is } \\
\text { communicating results } \\
\text { to clients. More } \\
\text { commonly, however, I } \\
\text { find myself explaining } \\
\text { concepts and processes } \\
\text { to colleagues who are } \\
\text { educated in different } \\
\text { areas of STEM. }\end{array}$ \\
\hline
\end{tabular}

\section{Staff reflections}

In addition to providing the basis of valuable engagement for Physics students, the label-writing exercise added value to the exhibition through the visitor experience, and hence met the Art Museum's mission to connect with the campus and the broader community. Significantly, the labels produced by the students provided an alternative way of conceptualising and understanding the selected art objects, outside the expected art historical view. In this way, the activity broadened the dialogue with gallery visitors about the artworks, opened up discussions around ways of looking at and responding to art, and demonstrated its transdisciplinary potential. For the curator, the best labels (for example, those displayed in Figure 1) went beyond the boundaries of the 
science discipline to say something about the art, weaving scientific observation into a broader discourse that incorporated the students' personal responses; the most successful encapsulated the science in a way that was both revelatory and expressive.

For the Physics lecturer, similarities in the nature of the two disciplines became clearer during this process - people involved in Art and in Physics each have a standard word for someone looking at something - a 'viewer' and an 'observer', respectively, which signifies how in both fields seeing is an important act.

This collaboration was mutually beneficial. Art and Physics each gained access and exposure to the other discipline. Scholars from the different disciplines gained perspective on their colleagues' field. Some of the particularities of this project aided its success. For example, the duration of the exhibition allowed time for the involvement of the students - for the students to see the artworks and write about them, for the required editorial, production and installation processes to occur, and for the student work to be on display for the art museum's audience. Another aspect of the project that was particularly effective was the wall labels' format as short pieces of text, since this was both professionally realistic and consistent with the suite of other science communication tasks that students were asked to complete in the module.

With the achievements of the project in mind, we have considered possible extensions to this science-art exercise. Scientists or science students could be involved in the selection of artworks for exhibitions. Using a model that has already been applied in curatorial studies at UQ, educational activities might take the form of two consecutive units. The first might involve science students in a hypothetical exercise (using the Art Museum's searchable collection management system and collection study facilities) to design an exhibition that connects their scientific discipline with artworks held by the university. Students with the most cohesive proposals might then be invited to work with Art Museum staff to realise their shows.

How could others use the strategy of having science students communicate the science in art - in relation to other sciences, with other art types, and in other exhibition situations? Light Play had a clear scientific premise. Botanical illustration, microscopic other-worlds captured via photography, aesthetically-appealing data visualisations, etc, all offer similar opportunities for explanations of science. Artist residencies in scientific contexts naturally produce artworks for which scientific commentary is valuable. Recognising that technological progress in light science has enabled the creation of different kinds of art, another possibility would be to focus on contemporary art that is based on particular technologies. In thinking about how our strategy could be applied to art relating to other topics, it is pertinent to recall the aim of IYL to broaden awareness of why light matters, and the curatorial observation underpinning Light Play that artists have been using light to explore social, personal or political issues (as well as to create visual effects). Wherever science intersects with social issues - the environment, geneticallymodified organisms, prosthetics and human augmentation ...- there is scope for artists and scientists to communicate together.

\section{Conclusions}

Through this project, students gained an appreciation that science and art can assist each other. They developed valuable written communication skills and were able to produce situationappropriate writing, as judged by in-course assessment and academic review. The activity provided a rare opportunity in undergraduate education for students to communicate about science to non-scientists. Moreover, the activity offered the genuine reward of public display at the end of a professionally realistic process. A positive effect on student engagement with science communication can be ascribed to this authenticity. 
As the students wrote about art, they consolidated their Physics knowledge. We can have confidence that these students know this physics because they can 'see' it in unfamiliar contexts and can explain it to others. The experience had personal impact on students, seen in their responses to the artworks, and an aspect of social responsibility in terms of consideration of their audience.

Beyond the positive student outcomes, this project was a successful interdisciplinary academic collaboration of mutual benefit, which provided a platform for significant interaction between arms of the university that usually operate separately. Through the partnership, the reach of the exhibition was extended, prompting cross-disciplinary discussions that drew on art, science and issues in the public domain. Capacity for further application of the strategy of science students discussing their discipline in relation to art holds promise for future interaction between the fields.

\section{Acknowledgements}

The Physics capstone students of 2015, particularly, for recent discussions: Alexander Johnston, Manning Young and Rebecca Chan (as well as permission to quote them), and Troy Cobb.

Lucy Mercer-Mapstone for design of original activity that was adapted for this situation, and for delivery of in-class communication training.

UQ Art Museum for supplying images of the artworks, and faciliating reproduction permissions.

\section{References}

Abisdris, G., \& Casuga, A. (2001). Atomic poetry: Using poetry to teach Rutherford's discovery of the nucleus. The Science Teacher, September, pp. 59-62.

About the Year of Light (2015). Retrieved from http://www.light2015.org/Home/About.html.

Jones, S., Yates, B.,\& Kelder, J.-A. (2011, June). Learning and Teaching Academic Standards: Science Standards Statement, Canberra: ALTC Report.

Kleine, H., \& Settles, G.S. (2008). The art of shock waves and their flowfields. Shock Waves, 17, pp. $291-307$.

Littley, S., \& Wegener, M.J. (2015). Light Play: Ideas, Optics, Atmosphere, exhibition catalogue. Retrieved from https://art-museum.uq.edu.au/whats/past-exhibitions/2015/light-play-ideas-optics-atmosphere.

Littley, S., Hennessey, P., Frost, A., Harrison, S., \& Holland, A. (2015). Peter Hennessey: Making It Real, exhibition catalogue. St Lucia: The University of Queensland Art Museum.

McInnis, C., Hartley, R., \& Anderson, M. (2000, December). What did you do with your science degree? A national study of employment outcomes for Science degree holders 1990-2000: Prepared for the Australian Council of Deans of Science. Melbourne: Centre for the Study of Higher Education, University of Melbourne. Retrieved from https://melbourne-cshe.unimelb.edu.au/_data/assets/pdf_file/0005/1494716/ScienceR.pdf.

Mercer-Mapstone, L.D., \& Kuchel, L.J. (2015). Teaching scientists to communicate: Evidence-based assessment for undergraduate science education. International Journal of Science Education, 37(10). DOI: https://doi.org/10.1080/09500693.2015.1045959.

Mercer-Mapstone, L.D., \&Kuchel, L.J. (2016). Integrating communication skills into undergraduate science degrees: A practical and evidence-based approach. Teaching \& Learning Inquiry, 4(2), pp. 1-14. DOI: https://doi.org/10.20343/teachlearninqu.4.2.11.

PI-ku: eight geekily poetic haiku about physics from Perimeter Institute (2017, November 23). Retrieved from https://insidetheperimeter.ca/pi-ku-eight-geekily-poetic-haiku-about-physics-from-perimeter-institute/.

Reflections: Physics Haiku (2002). Retrieved from https://www.andrew.cmu.edu/course/33131/more33131/docs/haiku.html.

Salamanca Arts Centre (2016). New Alchemists. Retrieved from https://www.salarts.org.au/event/new-alchemists/.

SymbioticA (2013). Semipermeable (+). Retrieved from http://www.symbiotica.uwa.edu.au/activities/exhibitions/semipermeable-.

SymbioticA (2019). Retrieved from http://www.symbiotica.uwa.edu.au/.

The Conversation (2019). Retrieved from https://theconversation.com/au.

UQ Art Museum (2017). New Alchemists. Retrieved from https://art-museum.uq.edu.au/whats/pastexhibitions/2017/new-alchemists

Wegener, M.J. (2013) Development of Threshold Learning Outcomes for Australian Graduates in Physics. Australian Physics, 50(3) p 89-93. Retrieved from http://www.acds-tlcc.edu.au/wpcontent/uploads/sites/14/2016/11/Physics-TLOs_Aust-Phys-50-3_published-2013.pdf. 